\title{
Point-of-Care Ultrasound in Undergraduate Medical Education: a Probe into its Feasibility
}

\author{
John Maclsaac \\ University of Ottawa, Faculty of Medicine, Ontario, Canada
}

ABSTRACT

Point of care ultrasonography (POCUS) has had its applications expand rapidly over recent years and across several medical specialties. Enough so that is has become an essential skill in most residency training programs across Canada. Despite this, there is little to no structured POCUS training at the medical undergraduate level. The goal of this commentary is to briefly introduce the value of POCUS in medical education; the feasibility of its integration; current barriers to its introduction; and the potential for students to be a possible solution until faculty can introduce a formal undergraduate POCUS curriculum.

RÉSUMÉ

L'échographie ciblée a vu ses utilisations agrandir rapidement dans les dernières années et parmi plusieurs spécialités médicales. Jusqu'au point où elle est devenue une habileté essentielle dans la plupart des programmes de résidence à travers du Canada. Malgré ça, il y a très peu d'enseignement sur l'échographie ciblée dans le domaine de l'éducation médicale du premier cycle. Le but de ce commentaire est d'introduire brièvement la valeur de l'échographie ciblée dans l'éducation médicale; la faisabilité de son intégration; les obstacles courants à son lancement; et le potentiel que les étudiants en prennent charge jusqu'au moment où la faculté peut introduire un programme formel d'échographie ciblée pour l'éducation médicale du premier cycle.

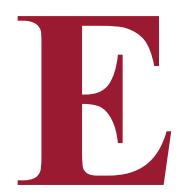
xpertise with point of care ultrasound (POCUS) is becoming a sought-after skill for new residents entering their training since a widening range of specialties are using it more frequently to aid in clinical diagnoses and guide procedures (1). The use of ultrasound for viewing heart, lung and abdominal pathology is commonplace, while central and peripheral venous access, biopsies, joint aspirations, nerve blocks and lumbar punctures are being done under ultrasound guidance with increasing frequency. This shift towards POCUS in clinical practice is imposing the need for medical student education and training in the technology. Attempts to incorporate POCUS into undergraduate medical education have been made, however resources and training are limited and there are significant instructional inconsistencies among the programs (1-8). Currently at the University of Ottawa, there is no formal ultrasound training in the undergraduate medical curriculum. As the use of this technology quickly evolves in modern medicine, it will be important that our medical education keeps pace. To maintain the clinical competence of medical students both at the clerkship level and as they enter residency, POCUS training will need to be incorporated into the undergraduate medical curriculum at uOttawa.
Basic POCUS competency requires only a limited number of sessions; students have reported a quick learning curve and demonstrated proficiency with the most clinically relevant ultrasound practices after only 5 instructional sessions $(5,9-11)$. At uOttawa, the addition of basic education in the procedural and diagnostic fundamentals of cardiac, thoracic and abdominal exams has been proven feasible without necessitating cuts to the current curriculum (12). One reason is its natural positioning within an anatomy syllabus; POCUS is described as an excellent anatomical educational tool, highly effective at facilitating the learning of anatomy and the physiologic and pathologic characteristics of many organ systems (13-16).

Our Faculty currently acknowledges the value of POCUS and its integration into other medical school curriculums. Initial thoughts on its integration at uOttawa will target the current anatomy syllabus. In anticipation, the Department of Anatomy purchased 9 ultrasound machines this year and ran two "pilot" Anatomy POCUS boot camps during the summer of 2018 to test possible methods of POCUS integration into its existing curriculum. Results showed that the 9 machines are sufficient to educate our class size using a rotatory schedule similar to what is already in place for anatomy classes. However despite these encouraging results, the development of a robust infrastructure for POCUS training will not be immediate; some barriers remain, slowing its integration.

Keywords: Point of care ultrasound; Medical education 
One major barrier to the incorporation of ultrasound training into most medical undergraduate curricula is the relatively small number of available instructors compared to the number of students. Competency in POCUS techniques is developed through supervised hands-on training, which requires more teachers than traditional didactic lecturing. With typical institutional limitations with finances and physician availability slowing the development of a formal POCUS educational infrastructure, a more creative temporizing solution for student education is necessary in the interim: training upper year students as instructors to lower year students. In this set-up, the problem of having a large number of students to teach can solve the problem of not having enough instructors (17). Several universities have validated the effectiveness of "peer mentoring" and its ability to deliver ultrasound training to large groups of students with a significantly reduced need for faculty resources (18-20). Demonstrations of this system show a single physician instructor can supervise up to four student-instructorled groups and effectively provide coaching and feedback with the consequent self-directed learning even providing added long-term benefits (21). There is also a definite benefit for student instructors; they get a valuable opportunity to develop teaching skills, which not only help to solidify understanding of the concepts but are also preparatory for future teaching roles encountered during residency training (22).

This broadening use of POCUS in medicine dictates that incoming residents should have some knowledge of ultrasound. However POCUS training has lagged behind at the undergraduate level, since traditional educational systems have substantial limitations in available instructors and time; therefore, students' participation in the teaching process could provide a solution to this problem. Results from other institutions suggest that peer mentoring can facilitate the large-scale implementation of ultrasound education in undergraduate medical curricula (17). Studies out of Canada, the UK, Australia and Spain all report that a small number of physician-trained students can successfully teach POCUS skills to lower year students with good results (18-20).

Experiences at our own institution from pilot trials of POCUS education echo what has been demonstrated at these other sites. Thus, peer mentoring is a valuable resource worth considering to integrate basic ultrasound education into the uOttawa undergraduate medical curriculum, at least as a temporizing measure until more robust educational infrastructure can be developed.

\section{REFERENCES}

1. Shokoohi H, Boniface $\mathrm{K}$, Kaviany $\mathrm{P}$ et al. An Experiential Learning Model Facilitates Learning of Bedside Ultrasound by Preclinical Medical Students. J Surg Educ. 2016;73(2):208-14.

2. Bahner DP, Royall NA. Advanced ultrasound training for fourth-year medical students: a novel training program at The Ohio State University College of Medicine. Acad Med J Assoc Am Med Coll. 2013;88(2):206-13.

3. Rao S, van Holsbeeck L, Musial JL, et al. A pilot study of comprehensive ultrasound education at the Wayne State University School of Medicine: a pioneer year review. J Ultrasound Med Off J Am Inst Ultrasound Med. 2008;27(5):745-9.

4. Hoppmann RA, Rao VV, Poston MB, et al. An integrated ultrasound curriculum (iUSC) for medical students: 4-year experience. Crit Ultrasound J. 2011;3(1):1-12.

5. Fernández-Frackelton $M$, Peterson $M$, Lewis RJ, Pérez JE, Coates WC. A bedside ultrasound curriculum for medical students: prospective evaluation of skill acquisition. Teach Learn Med. 2007;19(1):14-9.

6. Bahner DP, Adkins EJ, Hughes D, Barrie M, Boulger CT, Royall NA. Integrated medical school ultrasound: development of an ultrasound vertical curriculum. Crit Ultrasound J. 2013;25(1):6.

7. Gogalniceanu P, Sheena Y, Kashef E, Purkayastha S, Darzi A, Paraskeva P. Is basic emergency ultrasound training feasible as part of standard undergraduate medical education? J Surg Educ. 2010;67(3):152-6.

8. Heinzow HS, Friederichs $\mathrm{H}$, Lenz $\mathrm{P}$, et al. Teaching ultrasound in a curricular course according to certified EFSUMB standards during undergraduate medical education: a prospective study. BMC Med Educ. 2013;11;13:84.

9. Syperda VA, Trivedi PN, Melo LC, et al. Ultrasonography in preclinical education: a pilot study. J Am Osteopath Assoc. 2008;108(10):601-5.

10. Beltrán LM, García-Casasola G. Ultrasonography managed by internists: the stethoscope of 21st century? Rev Clin Esp. 2014;214:155-60.

11. Moore CL, Copel JA. Point-of-care ultrasonography. N Engl J Med. 2011;364:749-57.

12. Edgar L, Fracarro L, Park L, Pageau P, Ramnanan C, Woo M. Evaluation of medical student point of care ultrasonography education sessions using competency assessment tools. [abstract] 2018. AIME Annual Medical Education Day. University of Ottawa.

13. Kirkpatrick AW, Sirois M, Laupland KB, et al. Hand-held thoracic sonography for detecting post-traumatic pneumothoraces: the Extended Focused Assessment with Sonography for Trauma (EFAST). J Trauma. 2004;57(2):28895.

14. Kobal SL, Trento L, Baharami S. Comparison of effectiveness of hand-carried ultrasound to bedside cardiovascular physical examination. Am J Cardiol. 2005;96:1002-6.

15. Mircea PA, Badea R, Fodor D, Buzoianu AD. Using ultrasonography as a teaching support tool in undergraduate medical education: time to reach a decision. Med Ultrason. 2012;14:211-6.

16. Teichgräber UK, Meyer JM, Poulsen Nautrup C et al. Ultrasound anatomy: a practical teaching system in human gross anatomy. Med Educ. 1996;30: 296-8.

17. Garcia-Casasola, G, Sánchez FJ, Luordo D, et al. Basic Abdominal Point-ofCare Ultrasound Training in the Undergraduate: Students as Mentors. J UItrasound Med. 2016;35(11):2483-9.

18. Ahn JS, French AJ, Thiessen ME, Kendall JL. Training peer instructors for a combined ultrasound/physical exam curriculum. Teach Learn Med. 2014;26:292-5.

19. Balasooriya C, Olupeliyawa A, lqbal M. A student-led process to enhance the learning and teaching of teamwork skills in medicine. Educ Health (Abingdon). 2013;26:78-84.

20. Furmedge DS, Iwata K, Gill D. Peer-assisted learning —-beyond teaching: how can medical students contribute to the undergraduate curriculum? Med Teach. 2014;36:812-7.

21. Brydges R, Nair P, Ma I, et al. Directed self-regulated learning versus instructor-regulated learning in simulation training. Med Educ. 2012;46:648-56.

22. Chiem AT, Soucy Z, Dinh VA, et al. Integration of Ultrasound in Undergraduate Medical Education at the California Medical Schools: A Discussion of Common Challenges and Strategies From the UMeCali Experience. J Ultrasound Med. 2016;35(2):221-33. 